\title{
THE UNITY OF PHYSICAL AND MORAL EDUCATION: VALUE FOUNDATIONS
}

(C) 2020

Klychkov Sergey Aleksandrovich, lecturer of Physical and Special Tactical Training Department Samara Law Institute of the Federal Penitentiary Service of Russia (Samara, Russian Federation)

\begin{abstract}
The paper substantiates the urgency of the problem of educating a person whose body and spirit are in harmonious unity - a healthy person both physically and morally. As one of the ways to solve this problem, the development of a moral personality within the framework of physical education is proposed. Evidence of the relationship of the physical and moral development of man in the process of education is given. The situation is substantiated that education is an introduction to values and it is proved that education of a person in harmony of body and spirit is possible in the process of his involvement in the values of physical culture and moral values. The specificity of value is revealed as a conscious meaning that defines a person's attitude to the world, to people and to himself and shows the place of relations in moral culture and in physical culture of a person. It is proved that values can be both components of physical culture, embodying ideals and ideas about the standard of a physically perfect person, and components of moral culture (a standard of moral man). The correlation of moral values and values of physical culture is determined and specific values are identified that are the value foundations of the unity of physical and moral education: «freedom», «justice», «dignity», «culture», «moral perfection», «mercy», «intellectuality». The essence of the moral component of physical education is revealed. It consists in the fact that in the process of such education personality's attitude to health, to a healthy lifestyle, to himself and to other people, as well as human morality are developed.

Keywords: education; physical education; moral education; value; value bases; unity; morality; culture; physical culture; moral culture; moral values; physical culture values; relationships.
\end{abstract}

$* * *$

УДК 372.854

DOI 10.24411/2309-4370-2020-11306

Статья поступила в редакцию 09.01.2020

\section{ОПЫТ ПРЕПОДАВАНИЯ ДИСЦИПЛИНЫ «НЕОРГАНИЧЕСКАЯ ХИМИЯ» В АГРАРНОМ ВУЗЕ}

(C) 2020

\author{
Кондрашова Анжела Владимировна, кандидат химических наук, \\ доцент кафедры микробиологии, биотехнологии и химии \\ Саратовский государственный аграрный университет имени Н.И. Вавилова \\ (2. Саратов, Российская Федераичя)
}

Аннотация. В данной статье рассматривается опыт преподавания дисциплины «Неорганическая химия» для студентов 1 курса на кафедре микробиологии, биотехнологии и химии в Саратовском государственном аграрном университете. Обосновывается идея, что содержание курса химии направлено на слияние теории и практики. Как показывает практика, данная дисциплина состоит из прочтения лекций с применением мультимедийного сопровождения, из выполнения лабораторных работ, практических занятий, тестовых контрольных. Предложен способ организации самостоятельной работы среди студентов, что приводит к успешному освоению образовательной программы высшего образования. Приведены примеры образцов заданий входного контроля для контроля остаточных знаний, образцов тестовых заданий и вопросов для правильной оценки знаний студентов. Автор показывает, что проведение таких видов контроля знаний студентов позволяет оценить уровень усвоения материала и выявить проблемные моменты. В статье дана оценка тому, что для осознанной и целенаправленной подготовки к практическим занятиям, лабораторной работе и экзамену используют разработанное на кафедре учебное пособие. Автор статьи пришел к выводу, что преподаватель выступает помощником для студентов на их пути самостоятельного решения небольших научных задач.

Ключевые слова: образование; учебный процесс; занятия; кафедра; неорганическая химия; входной контроль; лекция; лабораторная работа; университет; самостоятельная работа; тестирование; контрольная работа; учебное пособие; преподаватель; студенты; аграрный вуз; первый курс; мультимедийное сопровождение.

\section{Введение}

В современных условиях система образования требует использования в учебном процессе различных форм проведения занятий $[1 ; 2]$. На базе ФГБОУ ВО «Саратовский государственный аграрный университет» студенты многих направлений подготовки на первом курсе изучают дисциплину «Неорганическая химия». Обучение дисциплине ограничивается первым семестром.

На кафедре микробиологии, биотехнологии и химии данная дисциплина включает изучение основ- ных вопросов общей и неорганической химии и состоит из прочтения лекций, выполнения лабораторных работ, тестовых контрольных, самостоятельной работы студентов.

Цель. Содержание курса направлено на слияние теории и практики. Студентам в ходе изучения дисциплины предстоит изучить и осмыслить большой объем теоретического и практического материала.

Методы и результаты исследований

Студентам предлагается входной контроль [3-5], целью которого является: 
- определение уровня знаний, полученных студентами на этапе предыдущего образования (школа, лицей, колледж);

- определение степени подготовленности студентов к изучению дисциплины «Неорганическая химия», предусмотренная учебным планом основной образовательной программы высшего образования;

- выявление преподавателем недостатков подготовленности обучающихся;

- адаптация студентов 1-го курса к учебному процессу в университете.

Входной контроль в вузе является контролем остаточных знаний по химии, который представляет собой небольшую контрольную работу. Всего во входном контроле 7 заданий продолжительностью 30-40 минут.

При решении заданий входного контроля студентам необходимо знать номенклатуру основных неорганических соединений; умение записывать формулы химических веществ, электронные формулы атомов химических элементов; знать типы химической связи; умение определять степень окисления элементов в химических соединениях и уравнивать окислительно-восстановительные реакции (табл. 1).

Таблица 1 - Образец задания входного контроля

\begin{tabular}{|c|c|}
\hline Задание & Вариант № 1 \\
\hline $\begin{array}{l}\text { 1. Сколько частиц } \\
\text { содержатся в... }\end{array}$ & ...5 моль хлорида натрия \\
\hline $\begin{array}{l}\text { 2. Напишите электрон- } \\
\text { ную формулу... }\end{array}$ & ...ванадия (23) \\
\hline 3. Напишите формулы... & $\begin{array}{l}\text {..оксида алюминия, се- } \\
\text { роводорода, ацетата ам- } \\
\text { мония, хромата натрия }\end{array}$ \\
\hline $\begin{array}{l}\text { 4. Укажите типы хими- } \\
\text { ческих связей в... }\end{array}$ & $\ldots \mathrm{HI}$ \\
\hline $\begin{array}{l}\text { 5. Напишите уравнение } \\
\text { для диссоциации... }\end{array}$ & ...азотной кислоты \\
\hline $\begin{array}{l}\text { 6. Расставьте степени } \\
\text { окисления } \\
\text { в соединении... }\end{array}$ & $\ldots \mathrm{K}_{2} \mathrm{CrO}_{4}$ \\
\hline $\begin{array}{l}\text { 7. Расставьте стехио- } \\
\text { метрические коэффи- } \\
\text { циенты и укажите } \\
\text { окислитель и восста- } \\
\text { новитель в реакции... }\end{array}$ & $\begin{array}{l}\ldots \mathrm{H}_{2} \mathrm{~S}+\mathrm{K}_{2} \mathrm{Cr}_{2} \mathrm{O}_{7}+\mathrm{H}_{2} \mathrm{SO}_{4}= \\
=\mathrm{S} \downarrow+\mathrm{Cr}_{2}\left(\mathrm{SO}_{4}\right)_{3}+\mathrm{K}_{2} \mathrm{SO}_{4}+\mathrm{H}_{2} \mathrm{O}\end{array}$ \\
\hline
\end{tabular}

Лекция является ведущим звеном всего курса обучения, способом изложения большого теоретического материала. Лекция должна давать основы научных знаний по соответствующей дисциплине, концентрировать внимание студентов на различных вопросах общей и неорганической химии [6; 7].

Перед проведением практического занятия читаются лекции. Это позволяет студентам лучше подготовиться к лабораторным работам. В основном лекции идут с мультимедийным сопровождением [8; 9].

Дополнением к лекциям являются разработанные на кафедре учебные пособия, в которых собран теоретический материал, лабораторные работы и примеры решения задач для самостоятельного решения [10; 11].

Для осознанной и целенаправленной подготовки к практическим занятиям, лабораторным работам и экзамену используют учебное пособие [12; 13], которое также может быть использовано для самостоятельного изучения дисциплины «Неорганическая химия».

Самостоятельная работа представляет собой совокупность аудиторных и внеаудиторных занятий, обеспечивающих успешное освоение образовательной программы высшего образования [14; 15$]$.

При обучении в вузе требования к данному виду работы возрастают по сравнению со школой. В рамках вуза самостоятельная работа может решать следующие задачи:

- приобретение дополнительных знаний по дисциплине «Неорганическая химия»;

- развитие навыков самоорганизации;

- выработка навыков самостоятельной профессиональной и учебно-исследовательской деятельности.

Для решения задач самостоятельной работы необходимо:

- наличие помещений для выполнения самостоятельной работы;

- связь самостоятельной работы с рабочей программой дисциплины «Неорганическая химия»;

- развитие преподавателями у студентов навыков самоорганизации [16].

Для правильной оценки знаний студентов необходимо проводить тестирование среди студентов, которое способствует повышению мотивации студентов к изучению дисциплины «Неорганическая химия». Тест выступает важной формой контроля знаний студентов по химии (табл. 2). При помощи тестов можно не только проверить уровень усвоения основных элементов курса химии, но и закрепить изученный материал $[17 ; 18]$.

Получение студентами полноценных знаний по неорганической химии невозможно без лабораторных работ. Выполнение такого вида работ позволяет студентам опытно подтвердить теоретические положения и законы химии, приобрести навыки работы с химическими реактивами, освоить приемы и методы проведения химического синтеза, а также анализировать результаты работ и делать выводы. При выполнении лабораторных работ студенты используют рабочую тетрадь и описание проводимой лабораторной работы [19; 20].

Пример методики выполнения лабораторной работы «Основные классы неорганических соединений»

\section{Опыт 1. Получение кислорода}

В пробирку поместить немного сухого перманганата калия и закрепить её в держателе. Подогреть содержимое пробирки, затем внести в пробирку тлеющую лучинку и убедиться в получении кислорода. После окончания опыта и охлаждения пробирки налить в неё немного дистиллированной воды и хорошо перемешать содержимое пробирки. Обратить внимание на цвет образовавшихся веществ и объяснить внешний эффект происходящей реакции с помощью химического уравнения.

\section{Опыт 2. Получение водорода}

В пробирку с газоотводной трубкой поместить небольшой кусочек цинка и добавить 5-7 мл разбавленной соляной кислоты. Выделяющийся газ (водород) собрать в течение 1-2 минут в пробирку, надетую кверху дном на конец газоотводной трубки. Закрыть пробирку пальцем и поднести её к пламени горелки. Открыть пробирку, вспышка с характерным «лающим» звуком указывает на присутствие водорода. Записать уравнение реакции получения водорода. 


\section{Таблица 2 - Образец тестовых заданий и вопросов}

\begin{tabular}{|c|c|}
\hline $\begin{array}{l}\text { 1. Расставьте данные веще- } \\
\text { ства по мере увеличения } \\
\text { степени окисления азота. }\end{array}$ & $\begin{array}{l}\text { A. } \mathrm{NO}_{2} \\
\text { Б. } \mathrm{N}_{2} \\
\text { B. } \mathrm{NH}_{3} \\
\text { Г. } \mathrm{N}_{2} \mathrm{O}_{5}\end{array}$ \\
\hline $\begin{array}{l}\text { 2. Какое количество веще- } \\
\text { ства (моль) лития вступило } \\
\text { в реакцию с водой, если } \\
\text { при этом выделилось } 1 \text { л } \\
\text { водорода (н.у.)? }\end{array}$ & $\begin{array}{l}\text { А. } 1,25 \\
\text { Б. } 0,09 \\
\text { В. } 1,22 \\
\text { Г. } 0,06\end{array}$ \\
\hline $\begin{array}{l}\text { 3. Какое вещество в реакции } \\
\mathrm{MnO}_{2}+\mathrm{H}_{2} \mathrm{SO}_{4}+\mathrm{FeSO}_{4}= \\
\mathrm{Fe}_{2}\left(\mathrm{SO}_{4}\right)_{3}+\mathrm{MnSO}_{4}+\mathrm{H}_{2} \mathrm{O} \\
\text { является окислителем? }\end{array}$ & $\begin{array}{l}\text { A. } \mathrm{MnO}_{2} \\
\text { Б. } \mathrm{FeSO}_{4} \\
\text { В. } \mathrm{MnSO}_{4} \\
\text { Г. } \mathrm{Fe}_{2}\left(\mathrm{SO}_{4}\right)_{3}\end{array}$ \\
\hline $\begin{array}{l}\text { 4. Сколько литров 2М рас- } \\
\text { твора } \mathrm{HCl} \text { надо израсходо- } \\
\text { вать при взаимодействии } \\
\text { с цинком для получения } \\
\text { 5,6 л водорода? }\end{array}$ & $\begin{array}{l}\text { А. } 0,25 \\
\text { Б. } 0,50 \\
\text { В. } 0,36 \\
\text { Г. } 0,35\end{array}$ \\
\hline $\begin{array}{l}\text { 5. Какой из предложенных } \\
\text { оксидов является } \\
\text { амфотерным? }\end{array}$ & $\begin{array}{l}\text { А. оксид натрия } \\
\text { Б. оксид алюминия } \\
\text { В. оксид серы (IV) } \\
\text { Г. оксид кальция }\end{array}$ \\
\hline $\begin{array}{l}\text { 6. Какое количество веще- } \\
\text { ства (моль) лития вступило } \\
\text { в реакцию с водой, } \\
\text { если при этом выделилось } \\
1 \text { л водорода (н.у.)? }\end{array}$ & $\begin{array}{l}\text { А. } 1,25 \\
\text { Б. } 0,09 \\
\text { В. } 1,22 \\
\text { Г. } 0,06\end{array}$ \\
\hline $\begin{array}{l}\text { 7. Чему равен заряд ядра } \\
\text { атома химического эле- } \\
\text { мента, расположенного } \\
\text { во } 2 \text { периоде, IVA группе? }\end{array}$ & $\begin{array}{l}\text { A. }+4 \\
\text { Б. }+12 \\
\text { В. }+8 \\
\text { Г. }+6 \\
\end{array}$ \\
\hline $\begin{array}{l}\text { 8. Какой вид химической } \\
\text { связи в молекуле } \\
\text { фтороводорода? }\end{array}$ & $\begin{array}{l}\text { А. ковалентная } \\
\quad \text { полярная } \\
\text { Б. ковалентная } \\
\quad \text { неполярная } \\
\text { В. ионная } \\
\text { Г. металлическая }\end{array}$ \\
\hline $\begin{array}{l}\text { 9. Чему равна массовая доля } \\
\text { серебра в ортофосфате } \\
\text { серебра? }\end{array}$ & $\begin{array}{l}\text { А. } 77,3 \\
\text { Б. } 80,5 \\
\text { В. } 71,0 \\
\text { Г. } 62,3\end{array}$ \\
\hline $\begin{array}{l}\text { 10. Чему равна масса } \\
\text { (в граммах) } 44,8 \text { мл фтора } \\
\text { (при н.у.)? }\end{array}$ & $\begin{array}{l}\text { А. } 0,076 \\
\text { Б. } 1,022 \\
\text { В. } 0,050 \\
\text { Г. } 0,071\end{array}$ \\
\hline
\end{tabular}

Опыт 3. Получение оксида и гидроксида магния

Взять пинцетом кусочек стружки магния и сжечь в пламени газовой горелки. Обратить внимание на цвет окалины, полученной на кончике пинцета. Оксид магния стряхнуть в пробирку, прилить 1-2 мл дистиллированной воды и 1-2 капли фенолфталеина. Наблюдать за изменением окраски индикатора. С помощью уравнений химических реакций объяснить происходящие явления.

\section{Опыт 4. Получение гидроксида алюминия}

В пробирку налить 5-7 капель раствора сульфата алюминия и добавить раствор гидроксида натрия. Наблюдать выделение белого аморфного осадка гидроксида алюминия. Полученный осадок разделить на 2 части: в одну пробирку добавить избыток гидроксида натрия, в другую - раствор соляной кислоты. Наблюдать, что происходит с осадками в обеих пробирках. Написать уравнения происходящих реакций.

\section{Опыт 5. Получение солей}

а) В пробирку налить 2-3 капли раствора нитрата свинца и столько же раствора иодида калия. Наблюдать за выпадением осадка. Записать уравнение происходящей реакции.

б) В пробирку прилить 2-3 капли раствора сульфата меди, добавить вначале 1-2 капли раствора гидроксида аммония. Что наблюдается? Затем добавить избыток гидроксида аммония до полного растворения осадка. Записать уравнение происходящей реакции.

Реактивы:

- сухой перманганат калия $\mathrm{KMnO}_{4}$;

- дистиллированная вода;

- кусочек цинка;

- разбавленная соляная кислота $\mathrm{HCl}$;

- стружка магния;

- индикатор фенолфталеин;

- сульфат алюминия $\mathrm{Al}_{2}\left(\mathrm{SO}_{4}\right)_{3}$;

- гидроксид натрия $\mathrm{NaOH}$;

- нитрат свинца $\mathrm{Pb}\left(\mathrm{NO}_{3}\right)_{2}$;

- иодид калия $\mathrm{KI}$;

- сульфат меди (II) $\mathrm{CuSO}_{4}$;

- гидроксид аммония $\mathrm{NH}_{4} \mathrm{OH}$.

Оборудование:

- держатель для пробирок;

- пробирки;

- лучинка;

- пробирка с газоотводной трубкой;

- газовая горелка;

- пинцет.

Перед выполнением лабораторной работы студенту необходимо внимательно и подробно изучить технику безопасности работы в химической лаборатории, а также изучить теоретический материал, прилагаемый к данному эксперименту. Также в рабочей тетради необходимо предварительно оформить таблицу к лабораторной работе (табл. 3).

Таблица 3 - Отчет о выполнении лабораторной работы

\begin{tabular}{|c|c|c|c|c|c|}
\hline $\begin{array}{c}\text { № } \\
\text { опы- } \\
\text { та }\end{array}$ & $\begin{array}{c}\text { Назва- } \\
\text { ние } \\
\text { опыта }\end{array}$ & $\begin{array}{c}\text { Условия } \\
\text { выполне- } \\
\text { ния }\end{array}$ & $\begin{array}{c}\text { Уравне- } \\
\text { ния } \\
\text { реакций }\end{array}$ & $\begin{array}{c}\text { Наблю- } \\
\text { дения }\end{array}$ & $\begin{array}{c}\text { Вы- } \\
\text { воды }\end{array}$ \\
\hline & & & & & \\
\hline
\end{tabular}

Во время проведения лабораторной работы студенты должны познакомиться с химической посудой, химическими реактивами и вспомогательными материалами, должны написать все те наблюдения, которые они получили во время проведения, и сделать соответствующие выводы по каждому проведённому опыту.

Преподаватель во время проведения лабораторных работ должен следить за их проведением, за соблюдением техники безопасности, помогать знакомиться с химическими реактивами и разъяснять трудные вопросы, которые возникли во время проведения.

\section{Заключение}

Использование на занятиях различных методов помогает преподавателю повысить уровень знаний студентов, активизировать познавательную активность и разнообразить работу со студентами как при изучении нового материала, так и при закреплении уже изученного.

Таким образом, преподаватель выступает помощником студента на его пути самостоятельного решения небольшой научной задачи. 


\section{Список литературы:}

1. Ряузова О.Ю. Специфика и взаимосвязь аудиторной и внеаудиторной работы // Вестник Московского университета МВД России. 2009. № 11. С. 31-33.

2. Платонова Р.И., Бубякина Е.В., Парфенов И.Я. Состояние и перспективы региональных вузов в современной системе высшего образования // Балтийский гуманитарный журнал. 2016. Т. 5, № 3 (16). C. $153-157$.

3. Князева Е.М., Юрмазова Т.А. Входной контроль знаний студентов технического университета по химии // Современные проблемы науки и образования. 2013. № 1. С. 233.

4. Колотова Г.К. Диагностика входного контроля знаний и умений студентов-первокурсников по химии // Дальневосточный аграрный вестник. 2009. № 4 (12). C. 14-27.

5. Ясюкевич Л.В., Бычек И.В. Оценка стартового уровня подготовки обучающихся при изучении профильной дисциплины // Современные наукоемкие технологии. 2016. № 4-2. С. 417-421.

6. Колычев Н.М., Семченко В.В., Левкин Г.Г., Сосновская Е.В. Лекция о лекции: учебное пособие. Омск: Омская областная типография, 2014. 80 c.

7. Баранников В.Г., Кириченко Л.В. Значение лекций в повышение эффективности обучения студентов // Учебно-методическая конференция по реализации ФГОС ВО и профессиональных стандартов. Пермь: ФГБОУ ВО «Пермский государственный медицинский университет им. академика Е.А. Вагнера» Минздрава России, 2017. С. 27-29.

8. Сидоркин А.Ф., К Кочетова Ж.Ю. Целесообразность использования компьютерных презентаций на аудиторных лекциях по химии // Теоретические и практические вопросы интеграции химической науки, технологии образования: всероссийская научнопрактическая конференция с международным участием. Улан-Удэ: Восточно-Сибирский государственный университет технологий и управления, 2016. C. $254-259$.

9. Шишлянникова Н.Ю., Демидова Н.Г., Т Тупицкая С.Л. Электронные презентаций лекций по химии: перспективы и проблемы // Высшее образование сегодня. 2015. № 3. С. 81-85.

10. Кондрашова А.В. Общая и неорганическая химия с элементами физической химии: учебное пособие. Саратов: Издательский центр «Наука», 2015.71 с.

11. Кондрашова А.В. Неорганическая химия: Химия элементов: учебное пособие. Саратов: Издательский центр «Наука», 2015. 40 с.

\section{THE EXPERIENCE OF TEACHING «INORGANIC CHEMISTRY» COURSE AT AN AGRICULTURAL UNIVERSITY}

(C) 2020

Kondrashova Anzhela Vladimirovna, candidate of chemical sciences, associate professor of Microbiology, Biotechnology and Chemistry Department Saratov State Agrarian University named after N.I. Vavilov (Saratov, Russian Federation)

Abstract. This paper discusses the experience of teaching «Inorganic Chemistry» course to the $1^{\text {st }}$-year-students of Microbiology, Biotechnology and Chemistry Department at Saratov State Agrarian University. The idea is substantiated that the content of the chemistry course is aimed at merging theory and practice. As practice shows, this course consists of giving lectures with the use of multimedia, performing laboratory work, practical exercises and test controls. The author proposes a method of organizing independent work among students, which leads to the successful development of the educational program of higher education. The paper contains some sample tasks of input control to control residual knowledge as well as sample test tasks and questions for student's knowledge correct as- 
sessment. The author shows that such types of students' knowledge control allow us to assess the level of material assimilation and identify problem points. The paper assesses the fact that a textbook developed by the department is used for a conscious and purposeful preparation for seminars, laboratory practice and exam. The author of the paper has come to the conclusion that the teacher acts as an assistant for students on their way to solve small scientific problems independently.

Keywords: education; studying process; classes; department; inorganic chemistry; input control; lecture; laboratory work; workshop independent work; testing; test; tutorial; teacher; students; agricultural university; first course; multimedia.

\title{
ТЕСТИРОВАНИЕ КАК СРЕДСТВО ОЦЕНКИ СФОРМИРОВАННОСТИ ЭКОЛОГИЧЕСКОЙ КОМПЕТЕНТНОСТИ СТУДЕНТОВ ПЕДАГОГИЧЕСКОГО ВУЗА
}

(C) 2020

\author{
Макарова Екатерина Александровна, кандидат педагогических наук, \\ доцент кафедры биологии, экологии и методики обучения \\ Степанова Екатерина Сергеевна, кандидат педагогических наук, \\ доцент кафедры химии, географии и методики их преподавания \\ Самарский государственный сочииально-педагогический университет (г. Самара, Российская Федераџия)
}

Аннотация. Статья посвящена проблеме формирования экологической компетентности будущих учителей, а также особенностям диагностики сформированности компонентов экологической компетентности. Цель статьи состоит в том, чтобы показать опыт реализации компетентностного подхода в профессиональной подготовке бакалавров направления подготовки 44.03.05 Педагогическое образование (с двумя профилями подготовки) и методические подходы к оцениванию процесса формирования профессиональных компетенций. В статье рассматриваются понятия «экологическое образование», «экологическая компетентность». Авторы определяют экологическую компетентность выпускника педагогического вуза как интегрированное качество личности, основанное на теоретических знаниях, практических умениях в области экологии и готовности будущего учителя к экологически адекватному и профессионально целесообразному поведению в ситуациях морального выбора. Экологическая компетентность студента представлена как сложное системное образование, включающая ряд компонентов (когнитивный, ценностно-мотивационный, профессионально-деятельностный). Описаны средства оценивания сформированности экологической компетентности у студентов, в частности педагогическое тестирование. В статье определены основные этапы конструирования педагогического теста и условия его реализации. Также представлены результаты педагогического эксперимента, реализованного на базе естественно-географического факультета Самарского государственного социально-педагогического университета. Использование тестирования в профессиональном образовании дает возможность определения соответствия содержания, уровня и качества подготовки студентов, а систематическое проведение тестового контроля позволяет оценивать процесс формирования экологической компетентности у студентов педагогического вуза.

Ключевые слова: экологическая компетентность; экологическое образование; экологическая культура; компетентностный подход; диагностика и контроль образовательных результатов; подготовка будущего учителя; бакалавриат; педагогический университет; тестирование; средства оценивания; качество подготовки студентов.

Проблема глобального экологического кризиса не теряет своей актуальности. С того момента как в 1992 году в ходе конференции, организованной Организацией объединенных наций в городе Рио-деЖанейро, рядом стран была сформулирована повестка, декларирующая переход к устойчивому развитию общества, большое значение приобрели вопросы экологического образования, воспитания и просвещения. Современное российское общество осознает важность экологического образования, что нашло свое отражение в:

- Федеральном законе от 29.12.2012 г. № 273-Ф3 «Об образовании в Российской Федерации» [1];

- «Экологической доктрине Российской Федерации», одобренной распоряжением Правительства Российской Федерации от 31.08.2002 г. № 1225-p [2];

- Указе Президента Российской Федерации от 19.04.2017 г. № 176 «О Стратегии экологической безопасности Российской Федерации на период до 2025 года» [3].
Категория «экологическое образование» относится к сложносоставным понятиям, и, по мнению ряда исследователей (С.В. Алексеев, И.В. Вагнер, Е.Н. Дзятковская, Д.С. Ермаков, А.Н. Захлебный, А.Ю. Либеров, Н.М. Мамедов, Т.М. Носова, В.Н. Панов, И.Н. Пономарева, И.Т. Суравегина), оно включает в себя экологическую образованность, экологическую грамотность, экологическую культуру, экологическую компетентность [4-7].

Осуществлять экологическое образование подрастающего поколения призваны педагоги. Профессиональная подготовка учителя представляет собой динамичную, самоорганизующуюся систему. Исходя из требований Федерального государственного образовательного стандарта высшего образования направления подготовки 44.03.05 Педагогическое образование (с двумя профилями подготовки), результатом профессиональной подготовки будущего учителя должен выступать комплекс компетенций (универсальных, общепрофессиональных и профессио- 